\title{
Analysis of the Physical and Chemical Properties of Biocomposite Materials Obtained from Feather Flour and Polypropylene
}

\author{
SEBASTIAN ARADOAEI ${ }^{1,2}$, VASILE BAHRIN ${ }^{2}$, MIHAELA ARADOAEI ${ }^{*}$, \\ MIRELA ALINA CONSTANTIN ${ }^{3}$, LUCIAN ALEXANDRU CONSTANTIN ${ }^{3}$, \\ IOANA IONESCU ${ }^{3}$ \\ ${ }^{1}$ SC Innovative Green Materials SRL, 55B Dimitrie Mangeron Blvd., 700050, Iasi, Romania \\ 2 "Gheorghe Asachi" Technical University of Iasi, Faculty of Electrical Engineering, Energetics and Applied Informatics, \\ Department of Electrical Engineering, 55 Dimitrie Mangeron Blvd., 700050, Iasi, Romania \\ ${ }^{3}$ National Research and Development Institute for Industrial Ecology - ECOIND, 71-73 Drumul Podu Dambovitei, 060652, \\ Bucharest, Romania
}

\begin{abstract}
The study is highlighting the possibility of modeling the properties of composite materials based on recycled polypropylene (PPR), flour feathers $(F F)$, and compatibilizers $(C)$. The composite materials with $10 \%$ and $20 \%$ feather flour content were mixed and processed with a two-stage extruder having four heating zones between $200-230^{\circ} \mathrm{C}$, in order to obtain granules. The granules were injected in various forms to evaluate the properties. The composite materials have been evaluated for determination of melt flow index $(1900 \mathrm{C} ; 2.16 \mathrm{~kg})$, density, Charpy impact, breaking strength, elongation at break, and the dielectric behavior. The results showed that the introduction of feather flour in the polymer matrix based on PPR leads to decreased flow properties as well as physical and mechanical properties. The solution in solving these deficiencies was to use compatibility agents, that would improve these properties. The physico mechanical properties were analyzed in order to identify a composite with optimal properties for industrial application.
\end{abstract}

Keywords: biocomposites, feather flour, polypropylene, analysis of physico-chemical properties

\section{Introduction}

In order to respond to the constraints of energy resources, pollution and environmental protection legislation, researchers have developed in recent years many composite materials. Composite materials are mixtures of two or more components of different nature whose properties complement each other resulting in a material with superior properties to the components. The advantages of composite materials are the possibility of modeling the properties in order to obtain versatile materials with applications in various fields.

The polymeric composite materials are composed of a basic polymeric matrix and a reinforcing agent that has the role of improving the mechanical properties of the polymeric matrix in order to replace in various applications classic materials as wood, plastic or aluminum. The disadvantages of these materials are related to the production and processing processes which are complex.

The reinforcing materials are natural plant or animal fibers that offer, low weight, reliability, corrosion resistance, low maintenance costs, but also a faster decomposition rate in comparison to conventional plastic.

In recent years, chicken feather fibers have come to the attention of researchers. Chicken feathers are waste resulting from the processing of chicken in the industry being produced in very large quantities worldwide. The disposal is difficult and expensive involving storage, burning or recycling in animal feed. Chicken feathers contain 90\% keratin, and owing extraordinary properties as thermal and mechanical resistance, provide sound insulation and are also a lightweight material [1-4]. Keratin is renewable, environmentally friendly, and biodegradable material, as of its natural origin, and chicken feathers could be used in the development of biodegradable materials, due to the chemistry of the hidro-

\footnotetext{
*email:: mihaela.aradoaei@academic.tuiasi.ro
} 
phobic/hydrophilic mixed surface which makes them partially compatible with all polymers that are usually predominantly hydrophilic or hydrophobic [5]. The benefit of using chicken feathers as a filling is the diminishment of the total cost of biocomposite materials.

In the present article, feather flour-reinforced composites with a content of up to $20 \%$ by weight were obtained using a two-stage extruder. The matrix-fiber interaction has been improved by using coupling agents which are increasing the degree of cross-linking in the interfacial region and provide a proper bonding result [6].

\section{Materials and methods}

\subsection{Materials}

The composites were prepared by mixing 10 and $20 \%$ feather flour (FF) with recycled polypropylene (PPR). In order to improve the adhesion between the components compatibilizers (C) were used in a percentage of $32 \%$. The composite materials were made with and without the compatibilizers, according to the recipes in Table 1. Recycled polypropylene was used as a reference for the properties.

Table 1. Recipes for biocomposite materials obtained from FF and PP

\begin{tabular}{|c|c|c|c|c|c|}
\hline \multirow{2}{*}{ Materials } & \multicolumn{5}{|c|}{ Recipes } \\
\hline & PPR & $\mathrm{PPR} / 10 \mathrm{FF}$ & $\mathrm{PPR} / 20 \mathrm{FF}$ & $\mathrm{PPR} / 10 \mathrm{FF} / 32 \mathrm{C}$ & $\mathrm{PPR} / 20 \mathrm{FF} / 32 \mathrm{C}$ \\
\hline PPR & 100 & 90 & 80 & 58 & 48 \\
\hline FF & $\mathrm{x}$ & 10 & 20 & 10 & 20 \\
\hline \multicolumn{6}{|l|}{ Compatibilizers } \\
\hline LLDPE & $\mathrm{x}$ & $\mathrm{x}$ & $\mathrm{x}$ & 10 & 10 \\
\hline Licowax PED 521 GR & $\mathrm{x}$ & $\mathrm{x}$ & $\mathrm{x}$ & 2.25 & 2.25 \\
\hline Vistamaxx & $\mathrm{x}$ & $\mathrm{x}$ & $\mathrm{x}$ & 2.25 & 2.25 \\
\hline Hostavin N30 & $\mathrm{x}$ & $\mathrm{x}$ & $\mathrm{x}$ & 0.5 & 0.5 \\
\hline $\mathrm{CaCO}_{3}$ & $\mathrm{x}$ & $\mathrm{x}$ & $\mathrm{x}$ & 17 & 17 \\
\hline
\end{tabular}

Feather flour was provided by S.C. Zafir S.A., Vaslui, Romania by processing feathers from slaughtered chickens Ross 308 breed. Feather flour was obtained by an automatic hydrolysissterilization-drying process using a hydrolysis/drying reactor. The steam pressure inside the destroyer was 2.8 bar and the temperature was $138^{\circ} \mathrm{C}$. After reaching the operating pressure, the pressure and temperature parameters were kept constant for 20-30 min ensuring optimal hydrolysis of feathers and sterilization of the product. After 20-30 min, the pressure dropped releasing water vapor and the product was dried. The physico-chemical properties of feather flour are presented in Table 2.

Table 2. Physico-chemical properties of FF

\begin{tabular}{|c|c|c|c|c|c|c|}
\hline \multirow{3}{*}{ Sample } & \multicolumn{7}{|c|}{ Parameter } \\
\cline { 2 - 7 } & $\begin{array}{c}\text { Moisture } \\
(\%)\end{array}$ & $\begin{array}{c}\text { Total protein } \\
\text { min. }(\%)\end{array}$ & $\begin{array}{c}\text { Crude fiber } \\
(\%)\end{array}$ & $\begin{array}{c}\text { Ash, max. } \\
(\%)\end{array}$ & $\begin{array}{c}\text { Calcium max. } \\
(\%)\end{array}$ & $\begin{array}{c}\text { Grain size max. } \\
(\mathrm{mm})\end{array}$ \\
\hline FF & 7 & $80-85$ & 3 & 4 & 0.33 & 3 \\
\hline
\end{tabular}

Polypropylene PPR in the form of granules was used as a polymeric matrix. A mixture of Licowax PED 521 GR, linear low density polyethylene (LLDPE) for better homogenization, $\mathrm{CaCO}_{3}$ to increase the strength and rigidity, Vistamaxx with the role of reducing the contact surface between the processing equipment and the composite material and Hostavin N3 ultraviolet stabilizing agent, without influencing its properties were used as compatibilizers.

\subsection{Composite preparation}

Feather flour was preconditioned before being used and had a moisture content of $6 \%$. The composite materials based on feather flour and compatibilizers were mixed in a high-speed mixer for 
homogenization. Subsequently, the mixed materials together with the polymer matrix were extruded using an extruder which was provided with 4 heating zones. The temperature was adjusted between 200$230^{\circ} \mathrm{C}$ to match the melting point of PPR. The extruder had a screw diameter of $110 \mathrm{~mm}$ and was equipped with two stages of compounding. The first stage had an L/D ratio of 2:1, the second stage had an L/D ratio of 3:1 and a maximum speed of $60 \mathrm{rpm}$.

Through the first stage of the extruder, the polymeric matrix of PPR was introduced, and through the second stage, the feather flour (FF) or the mixture of feather flour and compatibilizers (C) were introduced. This two-stage system allowed to development of composite materials with improved properties since the feather flour is not introduced into the extruder together with the polymer matrix. Through this process, the exposure for a longer time to high temperatures is avoided. Exposure of feather flour to high temperature may lead to burning and deterioration of fibers while the composite materials obtained might be brittle and exhibiting poor mechanical properties.

From the extruder, the composite material came out in the form of a cable that was cooled in a water bath and was cut into granules. After, the granules were injected into various shapes to test the physicalmechanical properties of the composite materials.

\subsection{Testing methods}

Morphological analysis was performed using Scanning Electron Microscopy - Quanta FEG 250 with STEM and EDX detectors to investigate a wide variety of materials and characterize the structure and composition with high-resolution images. The melt flow index $(1900 \mathrm{C} ; 2.16 \mathrm{~kg}$ ) was determined with Ray-Ran device - 5MPCA and the density at $230^{\circ} \mathrm{C}$ were performed using a $50 \mathrm{~mL}$ pycnometer and analytical balance. The Charpy impact test was performed on notched specimens with a pendulum hammer with a maximum energy of $1 \mathrm{~J}$, breaking strength and elongation at break was determined using an FPZ dynamo-meter with constant test speed $(1 \div 500 \mathrm{~mm} / \mathrm{min})$ and the dielectric properties were analyzed with broadband dielectric analyzer Concept 80 Novocontrol.

\section{Results and discussions}

\subsection{Scanning electron microscopy}

From the examination of the chicken feathers with electron microscopy (SEM) was observed the comb-type structure of the feather that offers great flexibility and resistance of feathers, Figure $1 \mathrm{a}$. On the main branch called rachis are several branches called barbs that form the flat part of the feather, and the barbs support numerous barbules [6,7].

After transforming the feather into flour, homogeneous particles with different forms and sizes varying between $49.51 \div 998.4 \mu \mathrm{m}$ are observed, but also porosities with diameters apparently regular, Figure $1 \mathrm{~b}$. The volume, thickness and stiffness of chicken feather rachis are not suitable for use as natural protein fibers due to the fact that become particles after hydrolysis. The barbs exhibit honeycomb shaped and this structure can act as a raw material for lightweight high-tech materials and the barbules contribute to the strength of the fibers.

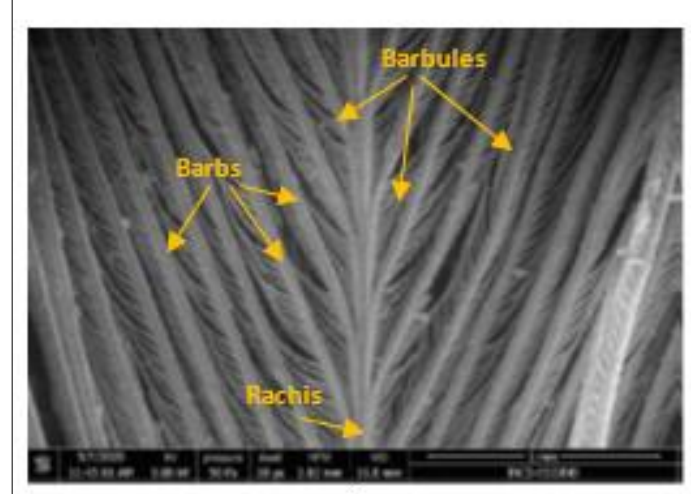

a)

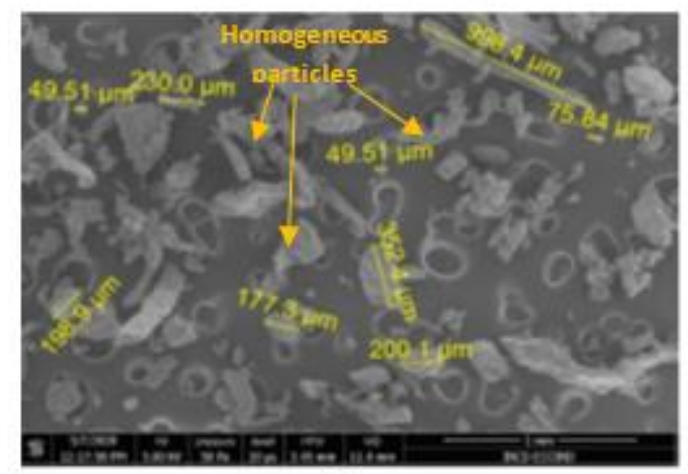

b)

Figure 1. SEM images for: a) the structure of feather and b) feather flour particles 
The SEM micrographs of composites with $10 \% \mathrm{FF}$ and $10 \% \mathrm{FF} / \mathrm{C}$ can be seen in Figure 2a,b. A good compatibility between materials is observed, and no voids in their surroundings, which denotes a good interfacial adhesion between the feather flour and the PP polymer matrix. Also, the SEM images of the composites in these figures show variability in the dispersion of feather flour in the PP matrix as of the use of compatibilizer agents, present in the $10 \% \mathrm{FF} / \mathrm{C}$ composite material [8-10].

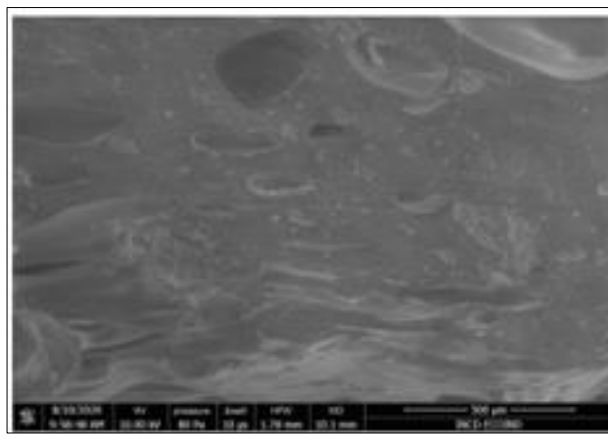

(a)

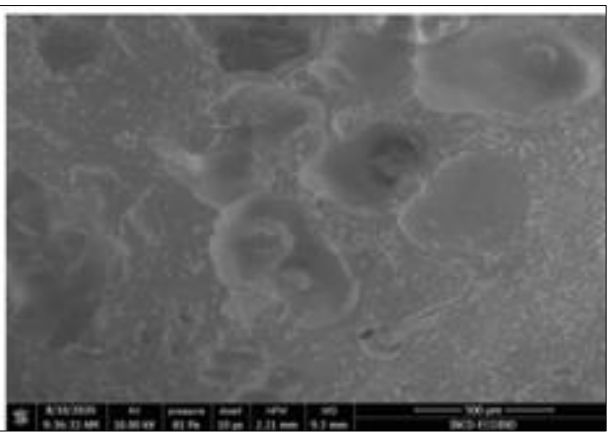

(b)

Figure 2. SEM images for: a) composites with $10 \% \mathrm{FF}$, and

b) composites with $10 \% \mathrm{FF} / \mathrm{C}$

\subsection{Melt flow index}

For the melt flow index determined at $230^{\circ} \mathrm{C}$ and weight $2.16 \mathrm{~kg}$, a decrease of the value for composites without compatibilizers is observed. The decrease is more pronounced in the case of PPR $/ 20 \%$ FF material, Figure 3 . In the case of composites with compatibilizer agents, the decrease of the melt flow index is less pronounced, only maximum one unit compared to the reference matrix. In conclusion, the use of compatibilizer agents maintains the melt flow index in an optimum technological range, for PPR/10FF/C and PPR/20FF/C materials [11].

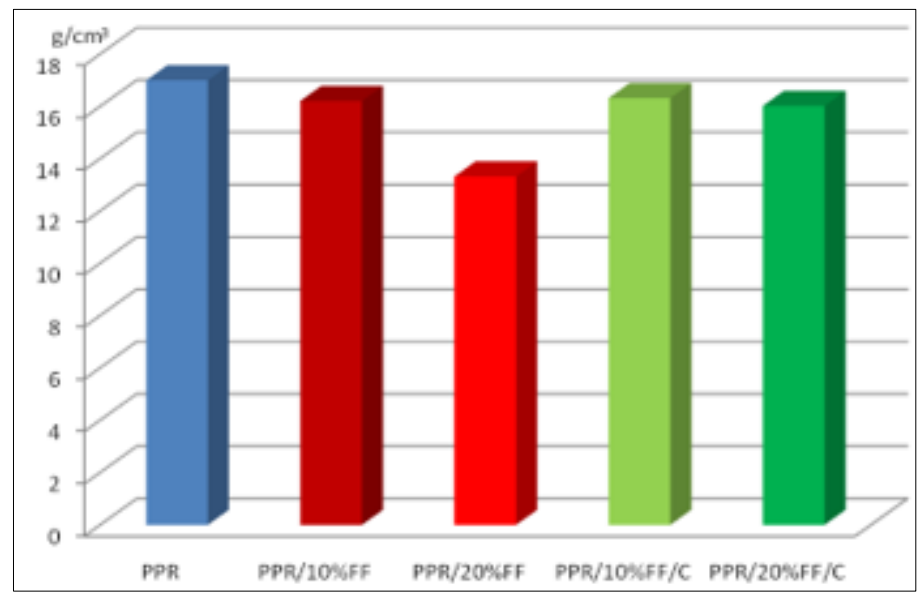

Figure 3. Melt flow index determined at $230^{\circ} \mathrm{C}$ and a weight of $2.16 \mathrm{~kg}$ for composite materials.

\subsection{Density}

In the case of composite materials without compatibilizers it is observed that by increasing the feather flour content from 10 to $20 \%$, the density at $230^{\circ} \mathrm{C}$ increases up to $0.94 \mathrm{~g} / \mathrm{cm}^{3}$ compared to $0.91 \mathrm{~g} / \mathrm{cm}^{3}$ of the PPR polymer matrix, due to the density of feather flour [12]. In the case of composite materials with compatibilizers this effect is more obvious as of the use of $\mathrm{CaCO}_{3}$ in a percentage of $17 \%$, Figure 4. This evolution of the density at $230^{\circ} \mathrm{C}$ with the increase of the feather flour content will lead to the increase of the specific weight of the final product resulting in direct implications on the production costs. 


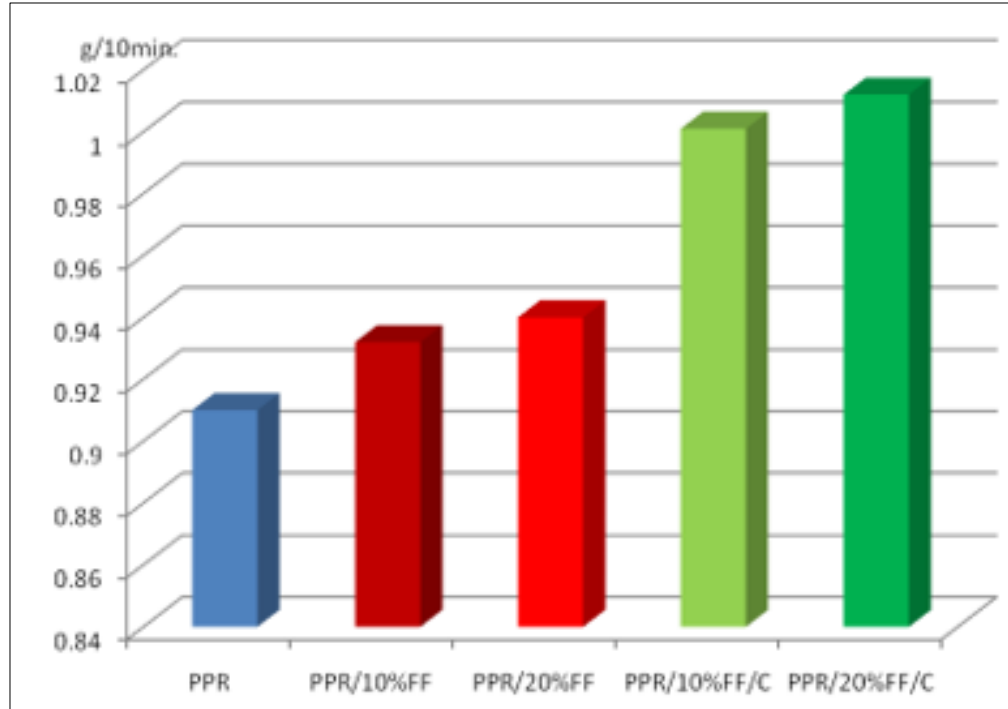

Figure 4. Density at $230^{\circ} \mathrm{C}$ for composite materials

\subsection{Charpy impact test}

CHARPY impact test results show an obvious decrease in values with the increase of the feather flour content, for all composite materials with or without compatibilizers. This behavior of the CHARPY impact test is due to the increase of the feather flour content which degrades when exposed to high temperature, but also due to amorphous behavior which is accentuated when the feather flour percentage is increased [13]. The introduction of a 2.25\% Vistamaxx elastomer does not visibly influence the results, Figure 5. To improve this property, tests can be resumed for a higher elastomer content but it becomes unprofitable from a financial point of view.

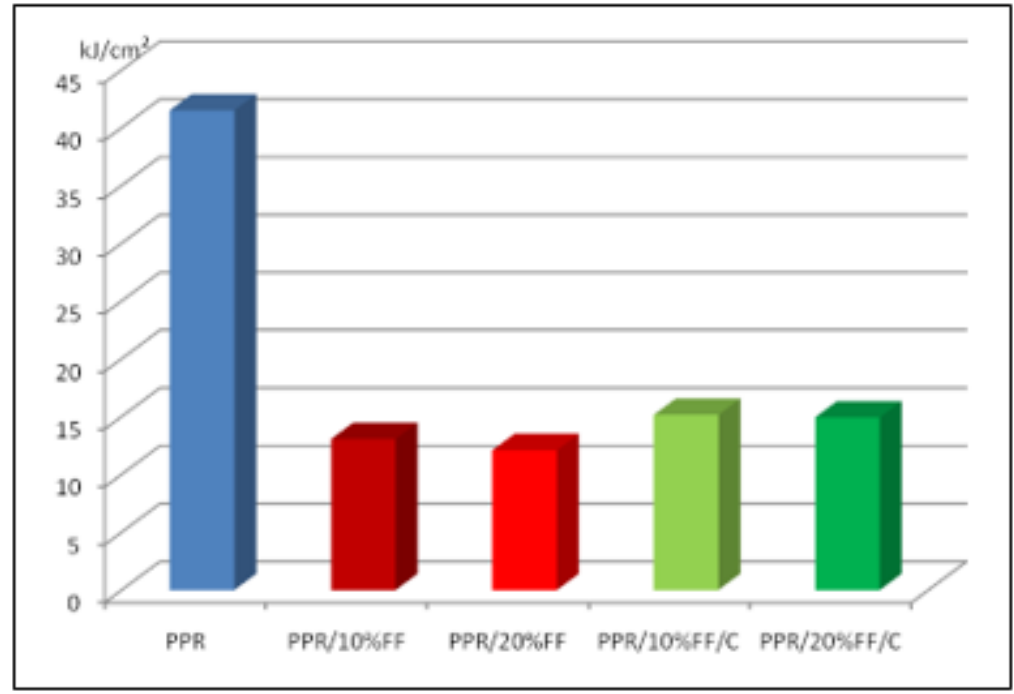

Figure 5. CHARPY impact test for composite materials

\subsection{Breaking strength and elongation at break}

For composites without compatibilizers, the breaking strength shows a decrease of about 53\% compared to the polymer matrix, mainly due to the thermal degradation of the feather flour. In the case of composite materials without compatibilizers the decrease in breaking strength is $45 \%$ fact attributed to the uniform dispersion of feather flour due to the presence of compatibilizers, Figure 6 . It can be concluded that thermal degradation of feather flour occurs in the process of achieving composites and the properties are dependent on feather flour content [14]. The results for elongation at break denote 
variations of the values for all composite materials. This variation may be attributed to the existing biomass agglomerations in the polymer. The composite RPP/20\%FF/C has a more pronounced decrease, and the downward trend is related to the increase in the percentage of feathers flour, Figure 7.

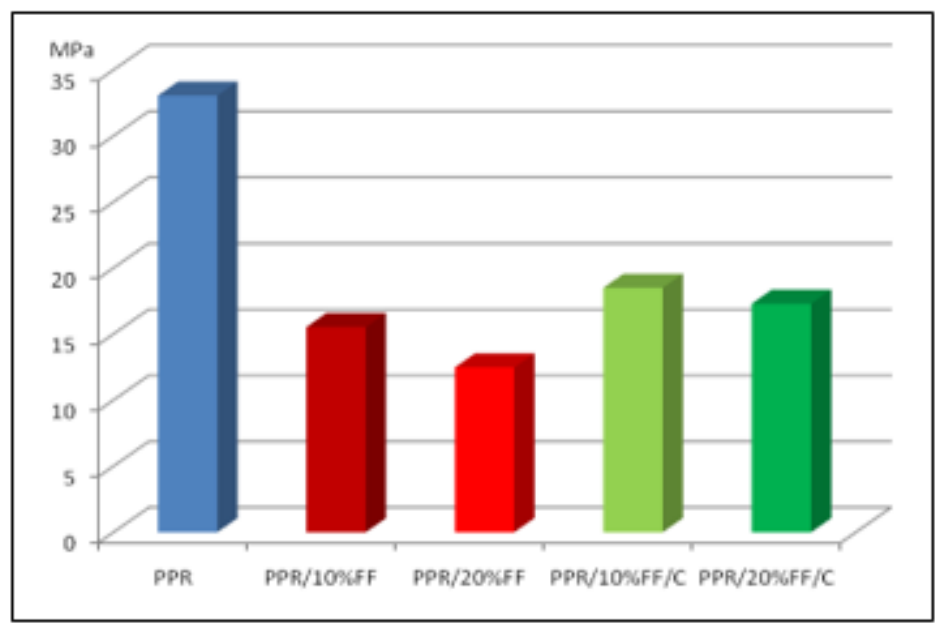

Figure 6. Breaking strength for composite materials

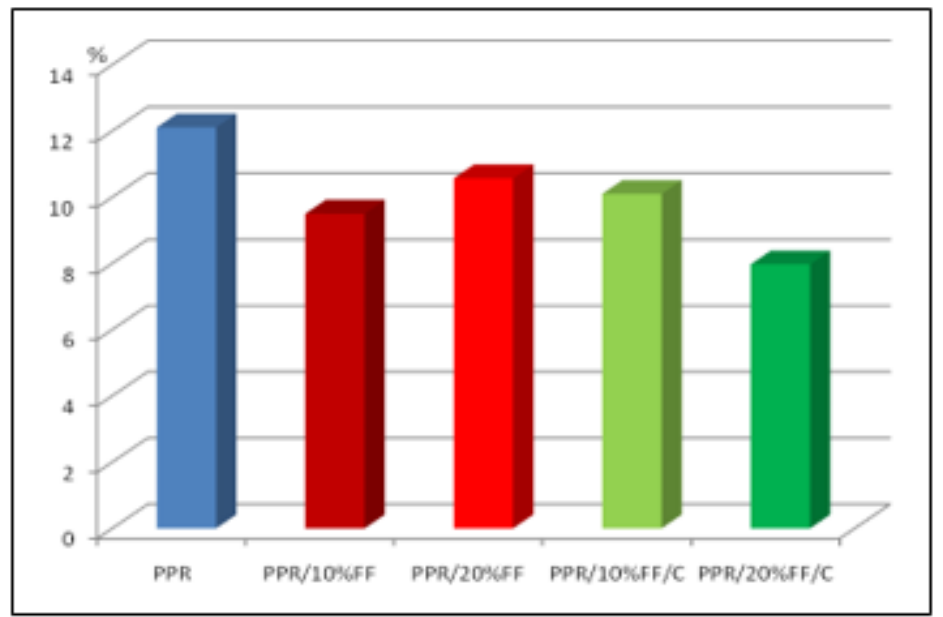

Figure 7. Elongation at break for composite materials

\subsection{Dielectric analysis}

From the dielectric analysis, it is observed that the presence of feather flour in the composite materials modifies the dielectric properties. The dielectric constant slightly modifies its values for the composites of $10 \%$ feather flour compared to the reference polymeric matrix. This change in the $0 \div 10^{3}$ $\mathrm{Hz}$ frequency range is due to the electrode polarization phenomenon [15, 16]. For composites with compatibilizer, the values of the dielectric constant also increase proportionally with the value of the feather flour percent and the highest value is registered for the PPR $/ 20 \% \mathrm{FF} / \mathrm{C}$ composite, for which the polarization effect of the electrode is more pronounced, Figure 8. This increase in dielectric constant is attributed to the presence of compatibilizing agents and especially $\mathrm{CaCO}_{3}$. Regarding the dielectric losses, the highest values were registered for the composites with $20 \%$ feather flour, in the case of $\mathrm{PPR} / 20 \% \mathrm{FF} / \mathrm{C}$ composite material, Figure 9 . For this material, the dielectric losses are more influenced by the amount of feather flour and less by the compatibilizers. 


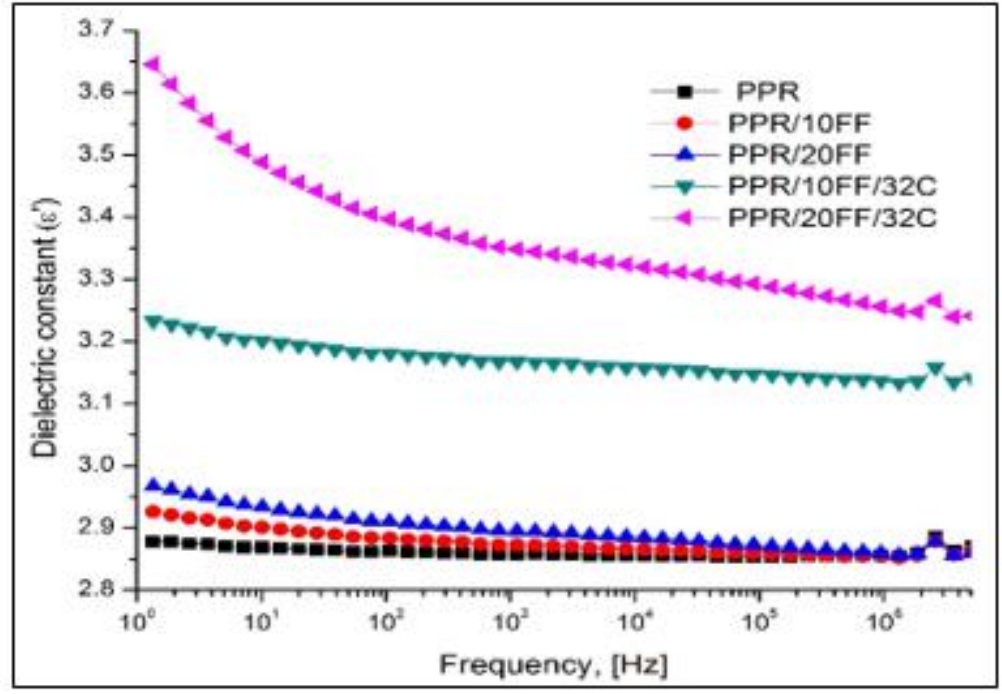

Figure 8. Dielectric constant for composite materials

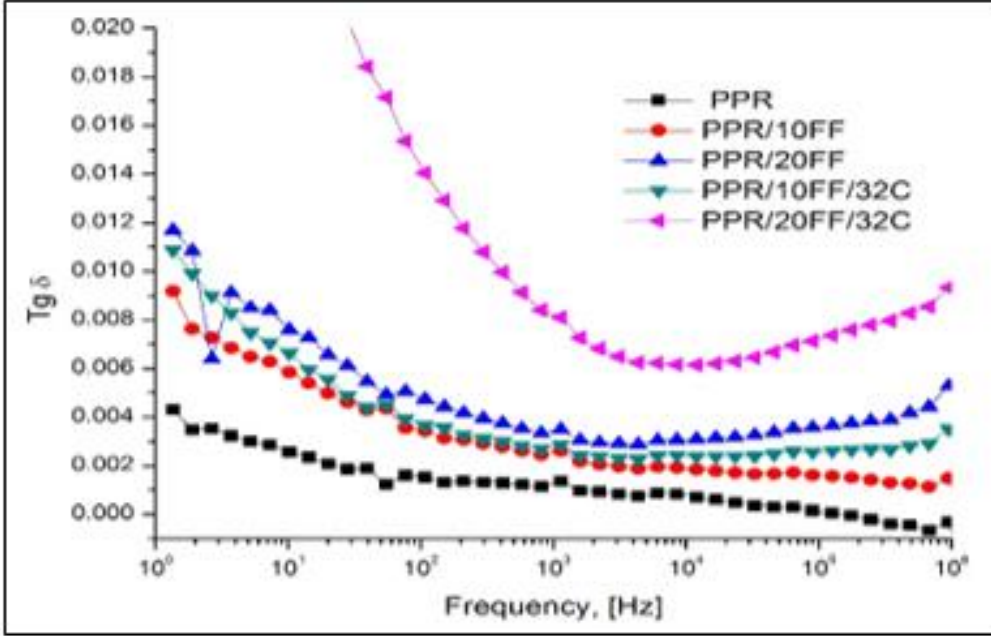

Figure 9. Dielectric losses for composite materials

\section{Conclusions}

The introduction of feather flour with or without compatibilizers in the PPR polymer matrix causes significant changes in physical and mechanical properties. The values of the melt flow index, Charpy impact test, breaking strength, elongation at break decreased by increasing the feather flour percentage, but the compatibilizers lead to the improvement of these decreases. The results obtained for the density at $230^{\circ} \mathrm{C}$ and the dielectric properties present an improvement when the feather flour loading percentage increases in presence of the compatibilizer. The results suggest that the PPR/10\%FF/C material has recorded good property values and is recommended for use on industrial tests.

Acknowledgments: All this work was realized with the support of Operational Programme Competitiveness 2014 - 2020, Project ID P_40_300, SMIS 105581, Subsidiary Contract 14352/2019.

\section{References}

1.V.SRIVATSAV RAVISHANKAR, M. RAMAKARISHNA Y. JYOTHI, T.N. BHANUPARAKASH, Mechanical and Thermal Properties of Chicken Feather Reinforced Epoxy Composite, AIP Conference Proceedings, 1992, 040 034, (2018), https://doi.org/10.1063/1.5047999

2. MENANDRO N. ACDA, Waste Chicken Feather as Reinforcement in Cement-Bonded Composites, Philippine Journal of Science 139 (2), 161-166, December 2010, ISSN 0031 ISSN 0031 - 7683. 
3. JOHRI, N., MISHRA, R. \& THAKUR, H. Synthesis and Characterization of Jute- and ChickenFeather-Fiber-Reinforced Polymer Hybrid Composites. Mech Compos Mater 54, 821-832 (2019). https://doi.org/10.1007/s11029-019-9786-4.

4. NING HU Composites and their properties, published: August 22nd 2012, DOI: 10.5772/2816, ISBN: 978-953-51-0711-8.

5. NARENDRA REDDY, Non-food industrial applications of poultry feathers, Waste Management Volume 45, November 2015, Pages 91-107, 0.1016/j.wasman.2015.05.023.

6. M. S. HUDA, W. F. SCHMIDT, M. MISRA, L. T. DRZAL, Effect of Fiber Surface Treatment of Poultry Feather Fibers on the Properties of Their Polymer Matrix Composites, Journal of Applied Polymer Science, 2012, 10.1002/app.38306.

7. TAMRAT TESFAYE, BRUCE SITHOLE, DERESH RAMJUGERNATH, VIREN CHUNILALL, Valorisation of chicken feathers: Characterisation of physical properties and morphological structure, Journal of Cleaner Production 149, pp.349-365, 2017, 10.1016/j.jclepro.2017.02.112.

8.DÉBORA D. BELARMINO, RASIAH LADCHUMANANANDASIVAM, LOILDE D. BELARMINO, JULIANA R. DE M. PIMENTEL, BRISMARK G. DA ROCHA, ALCIONE O. GALVÃO, SANIA M. B. DE ANDRADE, Physical and Morphological Structure of Chicken Feathers (Keratin Biofiber) in Natural, Chemically and Thermally Modified Forms, Materials Sciences and Applications, 3, 887-893, 2012, 10.4236/msa.2012.312129.

9. JUSTIN R. BARONE, WALTER F. SCHMIDT, Polyethylene reinforced with keratin fibers obtained from chicken feathers, Composites Science and Technology 65,173-181, 2005,

10.1016/j.compscitech.2004.06.011.

10. NARENDRA REDDY Non-food industrial applications of poultry feathers, Waste Management Volume 45, November 2015, Pages 91-107, 10.1016/j.wasman.2015.05.023.

11. DIANA SAMANTHA VILLARREAL LUCIO, JOSÉ LUIS RIVERA-ARMENTA, VALERIA RIVAS-ORTA, NANCY PATRICIA DÍAZ-ZAVALA, ULISES PÁRAMO-GARCÍA, NOHRA VIOLETA GALLARDO RIVAS AND MARÍA YOLANDA CHÁVEZ CINCO, Manufacturing of Composites from Chicken Feathers and Polyvinyl Chloride (PVC), Handbook of Composites from Renewable Materials, Volume 2, (159-174), 2017, 10.1002/9781119441632.ch25.

12. E JIMÉNEZ-CERVANTES AMIEVA, C VELASCO-SANTOS, AL MARTÍNEZ-HERNÁNDEZ, JL RIVERA-ARMENTA, AM MENDOZA-MARTÍNEZ AND VM CASTAÑO, Composites from chicken feathers quill and recycled polypropylene, Journal of Composite Materials, 2014,

$10.1177 / 0021998313518359$

13. M. UZUN, E. SANCAK, I. PATEL, I. USTA, M. AKALIN, M. YUKSEK, Mechanical behaviour of chicken quills and chicken feather fibres reinforced polymeric composites, Archives of Materials Science and Engineering 52(2), pp 82-86, 2011.

14. M. ZHAN, RICHARD P. WOOL, Mechanical properties of composites with chicken feather and glass fibers, Journal of Applied Polymer Science, 44013, 2016, 10.1002/APP.44013.

15.HAMCIUC, CORNELIU; HAMCIUC, ELENA; BACOSCA, IRINA; ET AL. Thermal and Electrical Properties of some Poly(ether-imide) Thin Films, Mater. Plast., 47(1), 2010, 11-15

16.SEBASTIAN ARADOAEI, ROMEO CRISTIAN CIOBANU, RALUCA DARIE, TRAIAN ZAHARESCU, ALINA CARAMITU, Green Materials Derived from Renewable Resource for Electrical Applications, Mater. Plast., 50(4), 2013, 310-313

Manuscript received: 22.09 .2020 